\title{
Removal of Heavy Metals (Fe, Mn and Cd) from Aqueous Solutions by Natural Zeolite and FeS Media
}

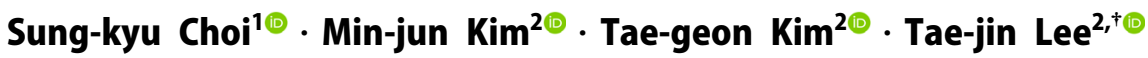 \\ 'Department of Environmental Energy Engineering, Graduate School of Convergence Science, Seoul National University of Science \\ and Technology \\ ${ }^{2}$ Department of Environmental Engineering, Seoul National University of Science and Technology
}

(Received May 25, 2021; Revised June 22, 2021; Accepted June 25, 2021)

Objectives: The adsorption characteristics of $\mathrm{Fe}, \mathrm{Cd}$, and $\mathrm{Mn}$ in aqueous solution using zeolite and FeS media were investigated by the adsorption isotherm and kinetic model analysis.

Methods: The adsorption characteristics of the heavy metals (Fe, Mn, Cd) were investigated using Langmuir or Freundlich adsorption isotherm. The analysis of pseudo-first or pseudo-second order reaction was also attempted to evaluate the rate limiting factor such as molecular diffusion or chemical adsorption on the absorbents.

Results and discussion: The adsorption of the heavy metals on the zeolite and FeS media was more suitable for the Langmuir adsorption isotherm, representing that mono-layer absorption on the surface and no interaction between the absorbed solutes. The order of adsorption preference to zeolite was $\mathrm{Fe}>\mathrm{Cd}>\mathrm{Mn}$, whereas the order of adsorption preference to $\mathrm{FeS}$ media was $\mathrm{Cd}>\mathrm{Fe}>\mathrm{Mn}$. The adsorption kinetics of zeolite and FeS media were more suitable for pseudo-secondary reactions than for pseudo-primary reaction.

Conclusions: The absorption capacity of $\mathrm{FeS}$ media for the heavy metals ( $\mathrm{Fe}, \mathrm{Cd}$ and $\mathrm{Mn}$ ) in aqueous solution was higher than that of zeolite. The adsorption pattern was suitable for the Langmuir adsorption isotherm, and has kinetic characteristic by chemisorption.

Keywords: Zeolite, FeS Media, Adsorption Isotherm, Heavy Metals, Adsorption Kinetics 


\title{
연구논문
}

\section{천연 제올라이트와 황화철 여재에 의한 수용액 중 중금속 $(\mathrm{Fe}, \mathrm{Mn}, \mathrm{Cd})$ 의 제거}

\author{
최성규 $^{1 \oplus} \cdot$ 김민준 $^{2} \cdot$ 김태건 $^{2 \odot ~} \cdot$ 이태진 $^{2,+\odot ~}$ \\ ${ }^{1}$ 서울과학기술대학교 융합과학대학원 에너지환경공학과 \\ ${ }^{2}$ 서울과학기술대학교 환경공학과
}

목적 : 제올라이트와 황화철 여재를 이용한 수중의 $\mathrm{Fe}, \mathrm{Cd}, \mathrm{Mn}$ 의 흡착양상을 등온흡착식과 흡착 동역학 모델 분석 을 통해 비교 검토하였다.

방법 : Freundlich 또는 Langmuir 등온흡착식을 이용하여 각 여재에 중금속 $((\mathrm{Fe}, \mathrm{Mn}, \mathrm{Cd})$ 의 흡착특성을 살펴보고, 유사-일차 또는 유사-이차 반응차수 분석을 통해 분자확산이나 화학적 흡착과 같은 흡착제의 제한요인을 규명하고 자 하였다.

결과 및 토의: 제올라이트 및 황화철 여재에 대한 중금속의 흡착은 Langmuir 흡착 등온식에 더 적합하였으며, 이는 표면의 단층흡수와 흡착된 용질 간 상호작용 없다는 것을 의미한다. 제올라이트에 대한 흡착 선호도는 $\mathrm{Fe}>\mathrm{Cd}>$ $\mathrm{Mn}$ 인 반면, 황화철 매체에 대한 흡착 선호도는 $\mathrm{Cd}>\mathrm{Fe}>\mathrm{Mn}$ 으로 나타났다. 제올라이트 및 황화철 여재는 유사일차반응보다 유사-이차반응에 더 적합하였다.

결론 : 수용액에서 황화철 여재의 중금속 $(\mathrm{Fe}, \mathrm{Cd}, \mathrm{Mn})$ 흡착량이 제올라이트보다 더 많았다. 흡착양상은 Langmuir 등온흡착식에 적합하였으며, 화학적 흡착(chemisorption)의 동역학적 특성을 가진다.

주제어 : 제올라이트, 황화철여재, 등온흡착식, 중금속, 흡착동역학

\section{1. 서 론}

중금속은 비중 4.0 이상의 금속으로, 대기, 수질, 토양, 생물 을 통해 인체로 흡수된다. 중금속은 쉽게 분해되거나 배출되 지 않고 생태계를 순환하면서 생물체 내에 침투하여 생물체 내의 농도가 높아지게 되고 결국 인체에 흡수되어 만성이나 급성독성을 일으키기도 하고, 특히 일부 중금속들은 여러 산 업활동에 의해 수계에 많이 유입된다. ${ }^{1,2}$ 인위적인 활동에 의 한 중금속 오염은 산업, 광업 및 농업에서 배출되는 폐기물에 의해 발생되고 특히 금속제련, 화학 산업 및 제조공정에서 많 이 발생되는 것으로 보고되고 있다. ${ }^{3,4)}$ 환경에서 중금속 오염 은 높은 인체 위해도와 유기물질과 같이 무해화되기 쉽지 않 는 처리상의 어려움으로 중요한 환경 이슈 중 하나이다. ${ }^{5)}$ 중 금속은 중추신경 기능의 손상이나 혈액 성분의 불규칙성을 초래하여 인체의 중요한 장기 일부분에 심각한 부작용을 일으 킬 수 있다. 중금속 중 $\mathrm{Cd}$ 이나 $\mathrm{Mn}$ 의 경우 호흡곤란과 신경문 제를 야기할 수 있으며,7), $\mathrm{Fe}$ 과 같은 금속은 필수 영양소이지 만 과도할 경우 매우 독성이 강한 것으로 알려져 있다. ${ }^{8)}$
일반적인 빗물의 중금속 함량은 해를 갈수록 증가하는 양상 을 보이고 있으며, 빗물 중 가중평균 값은 $\mathrm{Zn}>\mathrm{Pb}>\mathrm{Cu}>$ $\mathrm{Ni}>\mathrm{Cr}, \mathrm{As}>\mathrm{Cd}$ 순으로 나타났고, 중금속 농도와 관련하여 빗물 중 $\mathrm{Al}$ 및 $\mathrm{Fe}$ 농도 $15 \mu \mathrm{g} / \mathrm{L}$ 이상, $\mathrm{Cr}, \mathrm{Cu}, \mathrm{Mn}, \mathrm{Ni}, \mathrm{Zn}$ 및 $\mathrm{Ti}$ 은 $1 \sim 10 \mu \mathrm{g} / \mathrm{L}$, 그리고 $\mathrm{Cd}$ 은 $1 \mu \mathrm{g} / \mathrm{L}$ 이하의 관측 결과가 보고된 바 있다. ${ }^{9)}$ 따라서 물의 이용에 있어서 안정성을 확보 하기 위하여 수중의 중금속과 같은 미량유해물질의 처리 방법 에 대한 깊은 고찰이 필요하며, 중금속에 대한 강한 환경 규제 에 발맞추어 처리기술의 고도화가 필요한 시점이다.

중금속 처리에서는 보편적으로 $\mathrm{pH}$ 조정을 통한 직접적 침 전이나 응집제에 투입하여 화학적 결합을 촉진하는 형태의 침전이 있으며, 이중 $\mathrm{pH}$ 조정에 의한 수산화반응을 통한 중금 속 침전이 반응 공정의 단순성이나 적절한 처리효율을 확보할 수 있다는 측면에서 보편적 중금속 처리방법으로 이용되고 있다. ${ }^{10)}$ 중금속 처리에 있어서 수산화 반응을 이용한 직접 침 전 외에도 화학적 침전, 이온교환, 흡착, 막여과, 생물학적 처 리법 등 다양한 기술들도 많은 연구가 진행 중이다. ${ }^{11-14)}$

최근에 들어 중금속 처리를 더욱 촉진하기 위하여 한 가지 
이상의 처리 기작을 가지는 복합적 처리기술의 개발이 시도되 고 있는데, 이러한 시도 중 주목할 만한 것이 흡착제 표면에 특정물질을 고정화하여 흡착능을 가속화시키는 방법으로 처 리효율을 괄목할만하게 개선하기도 하였다. ${ }^{15-20)}$ 표면개질과 같은 방법으로 처리효율을 개선시키는 연구와 더불어 제올 라이트(zeolite)나 벤토나이트(bentonite), 파이라이트(pylite) 또는 소각재(fly ash)와 같이 자연환경에서 얻을 수 있는 경 제성 있는 흡착재료를 이용하는 연구 역시 최근 많이 진행되 고 있다. ${ }^{21)}$

천연 제올라이트는 나트륨이나 리튬 또는 암모늄의 흡착에 선호도가 큰 것으로 알려져 있으나, 제올라이트의 구성분 중 알루미늄과 실리케이트의 조성비에 따라 흡착 선호도는 달라 지는 것으로 알려진다. ${ }^{22)}$ 흡착제 중 파이라이트와 같이 황화 철이 주성분으로 구성된 광물흡착제를 이용한 중금속 흡착에 대한 연구도 최근 진행되고 있으며, 이는 황화철에 포함된 황 이온을 이용한 중금속의 불용화 기작을 주요한 기작으로 소개 하고 있다. 그러나 표면개질을 포함한 흡착제를 이용한 중금 속을 처리하는 기술의 적용에 있어서 흡착제들은 중금속의 종류에 따라 그 반응성이 각각 다르게 나타날 수 있으므로 중금속 처리에 있어서 대상 흡착제와 중금속의 종류에 대한 충분한 고찰이 필요하다.

본 연구에서는 파이라이트 광재의 주성분인 황화철을 여재 로 사용하여 수중에서 중금속의 처리효율을 살펴보고자 하였 으며, 그 방법으로 등온흡착식의 적용 및 흡착 반응 차수의 산정을 통하여 중금속의 처리기작을 해석하였다. 황화철 기반 입상 여재의 흡착특성은 Freundlich와 Langmuir 모델을 사용 하여 분석하였으며, 중금속과 여재의 흡착 형태를 추정하기 위해 반응차수를 분석을 통한 흡착 동역학 해석이 시도되었 다. 분석된 황화철 여재의 중금속 흡착특성은 일반적으로 흡 착제로 많이 사용되고 있는 천연 제올라이트의 흡착 양상과 비교하여 각 재료의 흡착능을 비교 평가하였다. 본 실험에서 는 $\mathrm{Fe}$ 과 $\mathrm{Mn}$, 그리고 $\mathrm{Cd}$ 을 대표 중금속으로 채택하였으며 본 연구에서 도출되는 연구결과는 광물 여재를 이용한 수중의 중금속 흡착을 위한 기초자료로 활용할 수 있을 것으로 판단 된다.

\section{2. 실험 재료 및 방법}

\subsection{Langmuir 와 Freundlich 등온 흡착 모델}

Langmuir는 고체 표면에 기체 분자나 원자가 흡착할 수 있 는 흡착점이 존재하며, 단분자층에 대응하는 흡착 에너지는 일정하고 흡착된 용질 사이에는 상호작용이 없다는 가정하에 서 흡착식을 전개한다. Freundlich 등온흡착식은 하나 이상의 피흡착물질에 대해 경쟁적 흡착의 형태와 주어진 피흡착제에 대한 비특이적이면서 다른 친화도를 가진 흡착특성을 나타낸 다고 알려져 있다. 등온흡착 모델에 의한 해석은 흡착제에 대
한 중금속의 흡착양상이 균질계 인지 혹은 비균질계의 표면에서 일어나는지에 대한 판단 근거가 될 수 있다. ${ }^{22,23)}$ 실험 대상 중금 속( $\mathrm{Fe}, \mathrm{Cd}, \mathrm{Mn})$ 에 대한 평형상태에서 흡착양상은 Langamuir와 Freundlich 등온흡착식인 Eq. (1)과 Eq. (2)를 이용하여 분석하 였으며, 최소자승법을 이용한 통계적 회귀분석은 Sigma Plot (ver. 10, systat software Inc., USA)을 이용하였다.

$$
q_{e}=\frac{x}{m}=\frac{q_{m} \times b C_{e}}{1+b C_{e}}
$$

식에서 $\mathrm{C}_{\mathrm{e}}=$ 평형농도 $(\mathrm{mg} / \mathrm{L}), \mathrm{q}_{\mathrm{e}}=$ 평형에서 흡착량 $(\mathrm{mg} / \mathrm{g})$, $\mathrm{q}_{\mathrm{m}}=$ 최대 흡착량 $(\mathrm{mg} / \mathrm{g}), \mathrm{b}=$ 결합에너지와 연관된 Langmuir 흡착계수 $(\mathrm{L} / \mathrm{mg}), \mathrm{x}=$ 활성탄에 흡착된 용질량 $(\mathrm{mg} / \mathrm{L})$, 그리고 $\mathrm{m}=$ 활성탄 주입량 $(\mathrm{g} / \mathrm{L})$ 이다.

$$
q_{e}=\frac{x}{m}=k \times C_{e}^{\frac{1}{n}}
$$

여기서 $\mathrm{k}=$ Freundlich 흡착용량계수(indicator of adsorption capacity)이고 $\mathrm{n}=$ Freundlich 흡착친화도(adsorption intensity) 이다.

\section{2. 흡착 동역학 실험}

투여량을 달리한 각 입상여재의 중금속에 대한 흡착 반응에 대한 동역학 기작을 해석하기 위해 두 가지의 모델이 사용되었 으며, 유사-일차반응식(Pseudo-first order equation)에는 Eq. (3)과 (4) 그리고 유사-이차반응식(Pseudo-second order equation) 에는 Eq. (5)와 (6)이 이용되었다. 유사-일차반응은 용액에서 여재의 흡착을 표현하는 범용적 속도 방정식이고, 유사-이차반 응은 흡착물과 흡착제 사이의 전자 교환이나 공유가 수반되는 화학적 흡착이 주 반응기작이라고 보고된 바 있다. ${ }^{24)}$

$$
\begin{aligned}
& \frac{d q}{d t}=K_{s 1}\left(q_{e}-q_{t}\right) \\
& \log \left(q_{e}-q_{t}\right)=\log \left(q_{e}\right)-\frac{K_{S 1}}{2.303} t \\
& \frac{d q}{d t}=K_{s 2}\left(q_{e}-q_{t}\right)^{2} \\
& \frac{t}{q_{t}}=\frac{1}{K_{S 2} \times q_{e}^{2}}+\frac{t}{q_{e}}
\end{aligned}
$$

여기서, $\mathrm{q}_{\mathrm{t}}$ 와 $\mathrm{q}_{\mathrm{e}}$ 는 일정시간 또는 평형일 때의 흡착능 $(\mathrm{mg} / \mathrm{g})$ 이 다. $\mathrm{K}_{\mathrm{s} 1}(\mathrm{~L} / \mathrm{min})$ 은 유사-일차방정식의 상수이고, $\mathrm{K}_{\mathrm{s} 2}\left(\mathrm{~g} / \mathrm{mg}^{*} \mathrm{~min}\right)$ 는 유사-이차방정식의 상수이다.

\section{3. 제올라이트와 황화철 여재의 합성}

황화철 여재는 $\mathrm{FeS} 1.52 \mathrm{~g} / \mathrm{mL}, \mathrm{CaCO}_{3} 0.44 \mathrm{~g} / \mathrm{mL}$, 그리고 
(a)

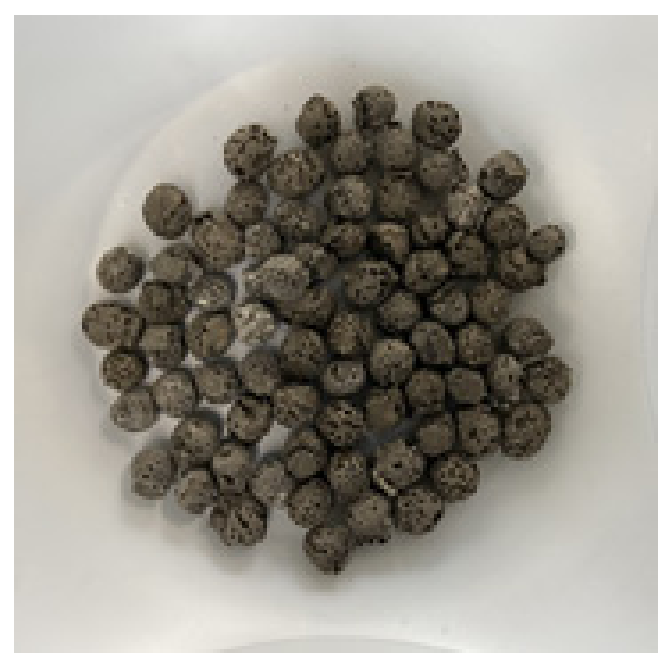

(b)

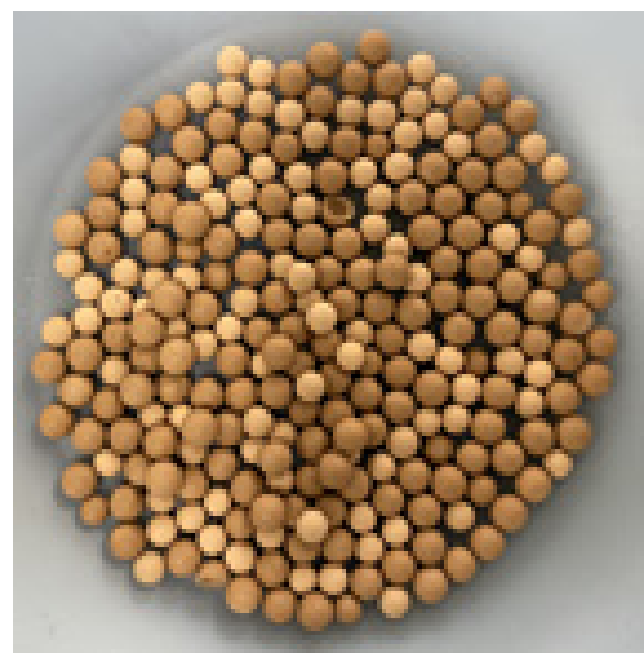

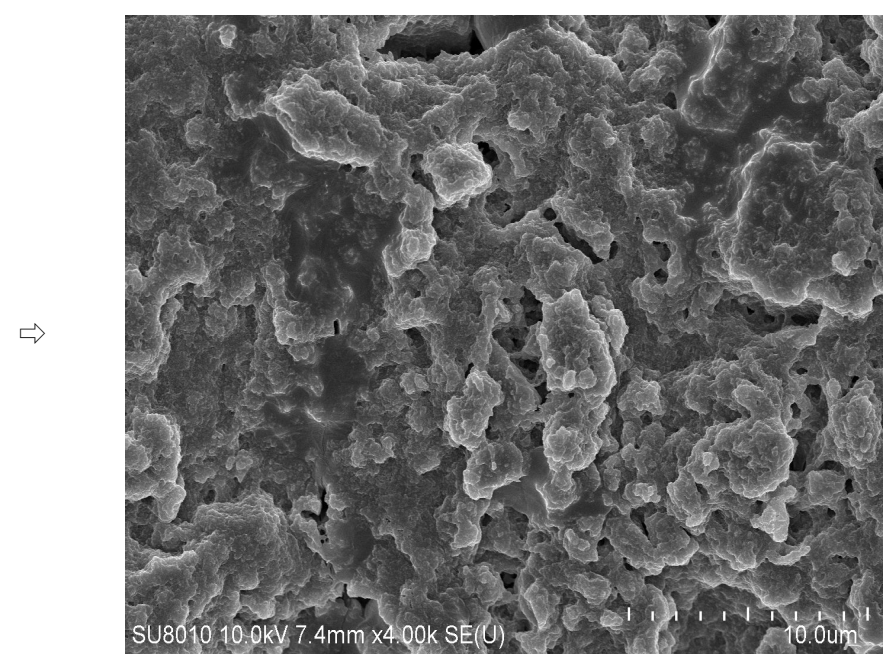

$4,000 X$

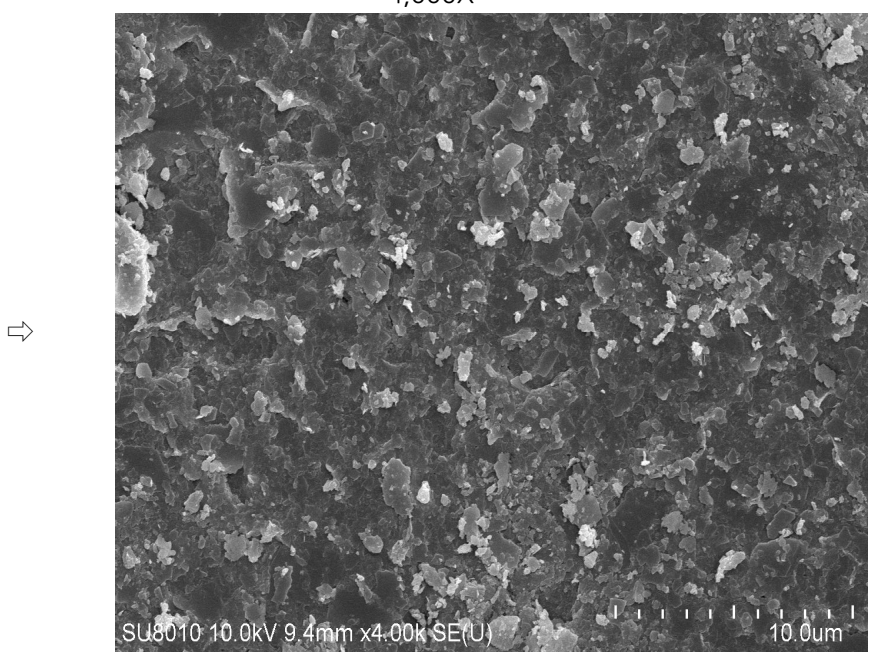

$4,000 X$

Fig. 1. Images of (a) FeS media and (b) zeolite from scanning electron microscope (SEM).

Sodium Silicate $1 \mathrm{~g} / \mathrm{mL}$ 의 농도로 잘 혼합한 후 $5 \mathrm{~mm}$ 구형 성형틀에 넣어 $105^{\circ} \mathrm{C}$ 에서 24시간 건조한 후 사용하였다. 제조 된 황화철 여재의 비표면적은 $2.26 \mathrm{~m}^{2} / \mathrm{g}$ 이였고, $4 \mathrm{~mm}$ 의 평균 입경과 $10.88 \%$ 의 공극률을 가진 것으로 분석되었다(Fig 1(a)). 흡착 비교실험에 이용된 제올라이트(제올라이트 $3 \not$, 금양소 재산업, 김해시)의 직경과 밀도는 약 $3 \mathrm{~mm}$ 와 $2.48 \mathrm{~g} / \mathrm{cm}^{3}$ 이였 고, 공극률과 비표면적은 각각 $26.79 \%$ 그리고 $23.67 \mathrm{~m}^{2} / \mathrm{g}$ 이 였다(Fig. 1(b)). 중금속 농도 분석과 표준용액의 제조를 위하 여 Sigma Aldrich에서 구입된 특급시약을 사용하였으며, 흡 착 실험은 $125 \mathrm{rpm}$ 과 $25^{\circ} \mathrm{C}$ 로 유지되는 항온조에서 실시하였 다. 중금속의 수화반응에 의한 침전을 최소화하기 위해 초기 $\mathrm{pH} 5.5$ 에서 중금속( $\mathrm{Fe}, \mathrm{Mn}, \mathrm{Cd})$ 과 여재를 $250 \mathrm{~mL}$ 의 부피를 가지는 회분식 반응기에 넣은 후 항온조에 위치하였으며, 시 간별로 시료를 채취하여 분석하였다. 실험데이터는 두 번의 실험을 통해 얻어진 결과값으로 평균값을 계산하여 분석하 였다.

\section{4. 중금속 분석}

$\mathrm{Fe}, \mathrm{Cd}, \mathrm{Mn}$ 의 분석은 먹는물 수질공정시험기준과 US EPA Method 7000A에 따라 Atomic Absortion Spectrophotometer (AAS, Perkin Elmer, USA)를 이용하였다. ${ }^{25,26)}$ 시료의 채수는 약 $10 \mathrm{~mL}$ 로 하고, Syringe membrane filter $(0.45 \mu \mathrm{m})$ 여과한 후 약 $60 \%$ 질산 $1 \mathrm{~mL}$ 를 넣어 polyethylene bottle에 넣어 분석 전까지 냉동 보관하였다.

\section{3. 결과 및 고찰}

\section{1. 제올라이트와 황화철 여재에 따른 등온흡착곡선}

제올라이트와 황화철 여재의 중금속 흡착 특성 분석에는 Langamuir와 Freunlich 등온흡착식이 이용되었으며, Langmuir 등온흡착식에 따르는 흡착 선호도는 Eq. (1)을 이용하여 $\mathrm{R}_{\mathrm{L}}$ $=1 /\left(1+\mathrm{b} \cdot \mathrm{C}_{0}\right)$ 을 계산할 수 있으며, 단층 흡착의 경우 $\mathrm{R}_{\mathrm{L}}>$ 1 이면 비선호적, $0<\mathrm{R}_{\mathrm{L}}<1$ 이면 선호적, $\mathrm{R}_{\mathrm{L}}=0$ 이면 비가역적으 로 정의되며, 여기서 $\mathrm{C}_{0}$ 는 초기 중금속 농도이다. Freunlich 

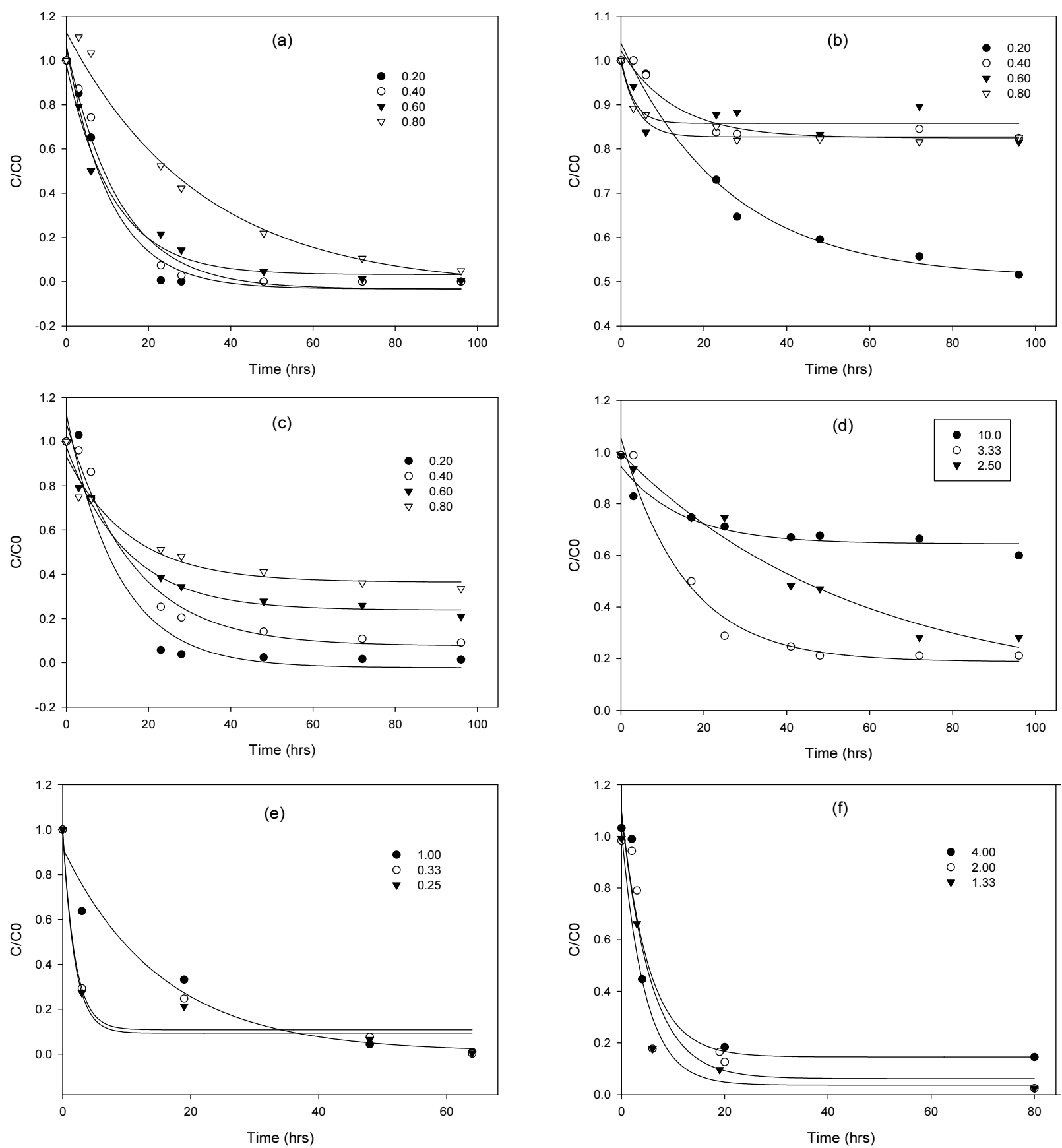

Fig. 2. Initial mass of heavy metal/mass of absorbent ( $\mathrm{mg} / \mathrm{g}$ ) of heavy metal concentration in the presence of a) Fe with zeolite, b) Mn with zeolite, c) Cd with zeolite, d) Fe with FeS media, e) Mn with FeS media, or f) Cd with FeS media.

등온흡착식의 $\mathrm{k}$ 와 $\mathrm{n}$ 은 물질 및 온도에 따라 변하는 상수이며, $\mathrm{k}$ 값이 클수록 흡착능이 크고, $\mathrm{n}$ 이 1 보다 크면 비우호적 흡착특성 을 나타내며, $\mathrm{n}$ 이 1 보다 작으면 우호적 흡착특성을 가진다고 보고된 바 있다. ${ }^{22)}$

본 실험에서는 중금속의 등온흡착 특성을 살펴보기 위해 $200 \mathrm{~mL}$ 의 회분식 반응기에 제올라이트 $\mathrm{g}$ 당 중금속의 질량을 각각 $0.2 \mathrm{mg}, 0.4 \mathrm{mg}, 0.6 \mathrm{mg}, 0.8 \mathrm{mg}$ 으로 설정하여 실험을 진행하였다. 황화철 여재의 경우 $200 \mathrm{~mL}$ 의 용액에 여재 $\mathrm{g}$ 당 $\mathrm{Fe}$ 의 경우 $2.50 \mathrm{mg}, 3.33 \mathrm{mg}, 10.0 \mathrm{mg}$ 의 초기농도를 설정하였
고, $\mathrm{Mn}$ 의 경우 $0.25 \mathrm{mg}, 0.33 \mathrm{mg}, 1.00 \mathrm{mg}$, 그리고 $\mathrm{Cd}$ 의 경우 $1.33 \mathrm{mg}, 2.00 \mathrm{mg}, 4.00 \mathrm{mg}$ 의 농도로 각각 설정하여 시간에 따른 각 중금속의 흡착량을 측정하였다. Fig. 2에 제올라이트 와 황화철 여재 투입에 따른 시간당 각 중금속의 농도변화 양상을 나타내었다.

Eq. (1)과 (2)의 Langamuir와 Freundlich 등온흡착식을 변형 하여 Fig.2에 나타난 제올라이트와 황화철 여재에 의한 중금 속의 농도 변화 값들을 선형화하였다. Fig.3은 등온흡착식을 선형화한 방정식을 나타내며, 선형화된 방정식을 이용하여 

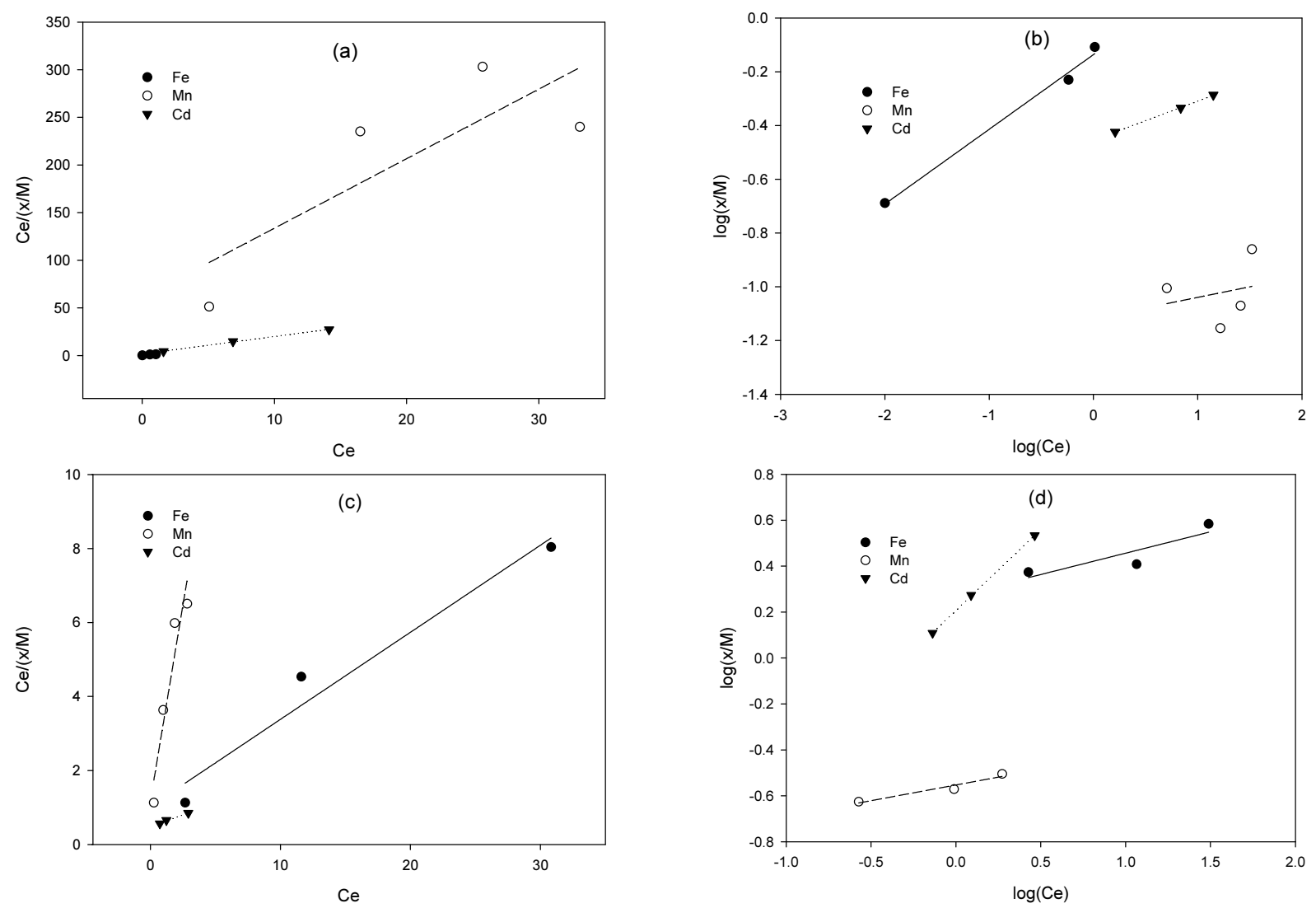

Fig. 3. Linearization of Langamuir ( $a$ and $c$ ) and Freundlich equation ( $b$ and d) of $\mathrm{Fe}, \mathrm{Mn}$, and $\mathrm{Cd}$ in the presence of zeolite and FeS media.

Table 1. Adsorption isotherm of the zeolite and FeS media on the heavy metals of Fe, Mn, Cd.

\begin{tabular}{|c|c|c|c|c|c|c|c|c|c|c|}
\hline & & \multicolumn{3}{|c|}{$\mathrm{Fe}$} & \multicolumn{3}{|c|}{$\mathrm{Mn}$} & \multicolumn{3}{|c|}{$\mathrm{Cd}$} \\
\hline & & $\mathrm{q}_{\mathrm{m}}$ & $b$ & $r^{2}$ & $\mathrm{q}_{\mathrm{m}}$ & $\mathrm{b}$ & $r^{2}$ & $\mathrm{q}_{\mathrm{m}}$ & $b$ & $r^{2}$ \\
\hline \multirow{3}{*}{$\begin{array}{l}\text { Langamuir } \\
\text { isotherm }\end{array}$} & Zeolite & 0.791 & 12.342 & 0.960 & 0.081 & 5.678 & 0.961 & 0.546 & 1.097 & 0.998 \\
\hline & $\begin{array}{c}\text { FeS } \\
\text { media }\end{array}$ & 4.424 & 0.229 & 0.961 & 0.472 & 1.805 & 0.908 & 7.868 & 0.262 & 0.992 \\
\hline & & $\mathrm{n}$ & $k$ & $r^{2}$ & $n$ & k & $r^{2}$ & $\mathrm{n}$ & k & $r^{2}$ \\
\hline \multirow{2}{*}{$\begin{array}{l}\text { Fruendlich } \\
\text { isotherm }\end{array}$} & Zeolite & 3.957 & 0.731 & 0.993 & 1.100 & 0.005 & 0.845 & 6.878 & 0.351 & 0.999 \\
\hline & $\begin{array}{c}\text { FeS } \\
\text { media }\end{array}$ & 5.376 & 1.864 & 0.781 & 4.417 & 0.299 & 0.791 & 1.418 & 1.613 & 0.999 \\
\hline
\end{tabular}

Langamuir와 Freundlich 등온흡착식 상수값들을 계산하여

Table 1 에 정리하였다.

Table 1에 나타난 바와 같이 Freundlich 등온 흡착식에서 제 올라이트나 황화철 여재에 의한 $\mathrm{Fe}, \mathrm{Mn}$, 그리고 $\mathrm{Cd}$ 의 흡착은 모두 $\mathrm{n}>1$ 이므로 $(6.878>\mathrm{n}>1.100)$ 비우호적인 흡착양상 을 나타내는 것으로 확인되었다. $\mathrm{Fe}, \mathrm{Mn}$, 그리고 $\mathrm{Cd}$ 의 흡착 의 경우 $0<\mathrm{R}_{\mathrm{L}}<1$ 이므로 $\left(1.60 \times 10^{-1}>\mathrm{R}_{\mathrm{L}}>8.03 \times 10^{-3}\right)$ Langamuir 등온 흡착식에서 우호적인 흡착형태를 가지는 것 으로 나타났다. 흡착특성에 대한 적합성을 구하기 위해 회귀 분석 값의 결정계수 $\left(\mathrm{r}^{2}\right)$ 를 확인해본 결과 Langamuir 식은 $0.908<\mathrm{r}^{2}<0.998$ 인 반면 Freundlich직선화에 따른 결정계
수는 $0.781<\mathrm{r}^{2}<0.999$ 으로 제올라이트와 황화철 여재의 흡 착은 Langamuir 등온흡착식에 더 적합하다는 것을 알 수 있 었다.

Table 2에서 보여지는 것과 같이 같은 제올라이트의 경우에 도 Langamuir 모델에 적합한 양상을 보이기도 하고 ${ }^{19,28)}$ 때로 는 Freundlich 모델에 적합하다고 평가받기도 한다. ${ }^{27,29)}$ 또한 몬모릴로나이트(montmorillonite)의 경우 이온에 따라 적합성 이 다르게 나타나기도 하였다. ${ }^{32)}$ 이러한 양상들은 수중에 포 함된 이온들의 공동효과에 의하기도 하고, 이온의 농도에 따 른 영향일 수 있다고 보고된 바 있다. ${ }^{22)}$ Illite나 kaolinite, 몬모 릴로나이트와 같은 자연에서 구해진 흡착제들의 일반적 흡착 
Table 2. Adsorption isotherm of heavy metals by the sorbents.

\begin{tabular}{cccc} 
Absorbents & Isotherms & Heavy metals & References \\
Zeolite & Freundlich & $\mathrm{Cr}^{3+}, \mathrm{Pb}^{2+}, \mathrm{Cd}^{2+}$ & 27) \\
\hline Zeolite & Langmuir & $\mathrm{Cu}^{2+}, \mathrm{Ni}^{2+}, \mathrm{Co}^{2+}, \mathrm{Fe}^{2+}$ & 28) \\
\hline Modified zeolite & Freundlich & $\mathrm{Pb}, \mathrm{Cu}^{2+}, \mathrm{Mn}, \mathrm{Ni}, \mathrm{Cd}$. & 29) \\
\hline Zeolite & Langmuir & $\mathrm{Cd}^{2+}, \mathrm{Fe}^{+3}, \mathrm{Ni}^{2+}$ & 19) \\
\hline Illite & Langmuir & $\mathrm{Pb}^{2+}$ & $30)$ \\
\hline Kaolinite & Langmuir & $\mathrm{Cu}^{2+}, \mathrm{Ni}^{2+}, \mathrm{Zn}^{2+}$ & $31)$ \\
\hline Montmorillonite & $\mathrm{Cu}^{2+}, \mathrm{Ni}^{2+}$ & $32)$ \\
\hline Zeolite & Langmuir/Freundlich & $\mathrm{Fe}^{2+}, \mathrm{Mn}^{2+}, \mathrm{Cd}^{2+}$ & This study \\
\hline FeS media & Langmuir & $\mathrm{Fe}^{2+}, \mathrm{Mn}^{2+}, \mathrm{Cd}^{2+}$ & This study \\
\hline
\end{tabular}

양상은 Langamuir 등온흡착식에 더 적합한 것으로 알려지지 만 피흡착제의 흡착 양상은 흡착제의 구성에 다분히 의존한다 고 보고된다. 따라서 흡착에 의한 중금속 제거 기작에 대한 해석은 흡착제의 구성성분과 피흡착물의 조성비 등 여러 환경 요인들이 종합적으로 검토되어야 한다. Table2에 기존의 연 구결과와 본 실험에서 사용된 여재의 흡착양상을 비교하여 제시하여 보았다. 본 실험에서 사용된 제올라이트와 황화철 여재의 흡착 양상은 Langamuir 모델에 만족하였고, 점토광물의 일반적 흡착양상과 유사하게 작용한다는 것을 알 수 있었다. 흡착선호도에 있어서 제올라이트의 경우 $\mathrm{Mn}$ 에 비하여 $\mathrm{Cd}$ 이나 $\mathrm{Fe}$ 에 의한 최대 흡착능 $\left(\mathrm{q}_{\mathrm{m}}\right.$ of $\mathrm{Fe}=0.791 \mathrm{mg} / \mathrm{g} ; \mathrm{q}_{\mathrm{m}}$ of $\mathrm{Mn}=0.081 \mathrm{mg} / \mathrm{g} ; \mathrm{q}_{\mathrm{m}}$ of $\mathrm{Cd}=0.546 \mathrm{mg} / \mathrm{g}$ )이 높게 나타났으며, $\mathrm{Cd}$ 보다는 $\mathrm{Fe}$ 의 흡착이 더 원활하게 일어난다는 것을 알 수 있었다. 황화철 여재의 경우 $\mathrm{Cd}$ 의 흡착이 가장 많이 일어났으 며 $\left(\mathrm{q}_{\mathrm{m}}\right.$ of $\mathrm{Fe}=4.424 \mathrm{mg} / \mathrm{g} ; \mathrm{q}_{\mathrm{m}}$ of $\mathrm{Mn}=0.472 \mathrm{mg} / \mathrm{g} ; \mathrm{q}_{\mathrm{m}}$ of $\mathrm{Cd}$ $=7.868 \mathrm{mg} / \mathrm{g}), \mathrm{Fe}$ 과 $\mathrm{Mn}$ 순으로 흡착 선호도가 있다는 것을 보여준다.

흡착 기작에 있어서 제올라이트는 complexation, chemisorption, adsorption-complexation on surface and pores, micro precipitation, ion exchange 등이 작용할 수 있다고 보고되었고 ${ }^{33)}$, 황화철 여재의 경우도 유사한 반응들이 진행될 수 있으나 특히 황화철 여재에 의한 흡착 형태는 Eq. (7) Eq. (12)와 같은 화학반응에 의한 micro precipitation이 부가적으로 진행 되고 ${ }^{27)}, \mathrm{MnS}$ 나 $\mathrm{CdS}$ 의 용해도적 $\left(\mathrm{K}_{\mathrm{sp}}\right)$ 값이 각각 $3 \times 10^{-14}$ 과 $8 \times 10^{-28}$ 임을 고려하였을 때, 작은 용해도적 값을 가지는 중금 속의 경우 수용액 상 불용성 입자로 형성되기 쉽고, 여재에 대한 이러한 불용성 입자의 흡착이 용이하게 진행될 수 있을 것으로 판단되었다. 따라서 등온 흡착식에서 보여진 두 여재의 흡착 양상이 비록 균질계의 표면 흡착반응이라는 공통성을 가지고 있으나 $\mathrm{Fe}, \mathrm{Mn}$, 또는 $\mathrm{Cd}$ 에 대한 황화철 여재에서 일어날 수 있는 흡착기작과 제올라이트의 흡착기작은 서로 상이하고, 흡착선호도도 동일하지 않다는 것을 알 수 있었다.

황화철 여재에서 $\mathrm{Fe}$ 의 흡착과 관련하여 황화철 여재에 포함 된 철이온에 의해 Eq. (7)과 같이 수용액에서 철이온의 농도를
증가시킬 수 있는 가능성이 있으나 수용액 중 철이온의 농도 가 오히려 제올라이트보다 낮게 검출되는 것은 Eq. (12)에서 보여지는 것과 같이 황화철 여재에 포함된 $\mathrm{CO}_{3}{ }^{2+}$ 에 의해 $\mathrm{FeCO}_{3}$ 의 $\left(\mathrm{K}_{\mathrm{sp}}=3.13 \times 10^{-11}\right)$ 형태로 침전될 수 있는 것으로 판단하였다.

$$
\begin{aligned}
& \mathrm{FeS}_{(\mathrm{s})}+\mathrm{H}+\Leftrightarrow \mathrm{Fe}^{2+}+\mathrm{HS}^{-} \\
& \mathrm{M}^{2+}+\mathrm{HS}^{-} \Leftrightarrow \mathrm{MS}_{(\mathrm{s})}+\mathrm{H}^{+} \\
& \mathrm{FeS}_{(\mathrm{s})}+\mathrm{M}^{2+} \Leftrightarrow \mathrm{MS}_{(\mathrm{s})}+\mathrm{Fe}^{2+} \\
& \mathrm{FeS}(\mathrm{s})+\mathrm{M}^{2+} \rightarrow \mathrm{FeS}-\mathrm{M}^{2+} \\
& \mathrm{M}^{2+}+\mathrm{nH}_{2} \mathrm{O} \rightarrow \mathrm{M}(\mathrm{OH})_{\mathrm{n}}^{(2-\mathrm{n})+}+\mathrm{nH}^{+} \\
& \mathrm{M}^{2+}+\mathrm{CO}_{3}^{2-} \rightarrow \mathrm{MCO}_{3}
\end{aligned}
$$

요약해 보면 Langamuir와 Freundlich 등온 흡착식에 의한 중금속의 최대 흡착량의 비교를 통해 제올라이트의 경우 흡착 선호도는 $\mathrm{Fe}>\mathrm{Cd}>\mathrm{Mn}$ 이였고 황화철 여재의 경우 $\mathrm{Cd}>$ $\mathrm{Fe}>\mathrm{Mn}$ 인 것으로 나타났으며, 흡착량에 있어서 황화철의 중 금속 제거량이 제올라이트의 제거량보다 뛰어난 것으로 판단 되었다.

\section{2. 제올라이트와 황화철 여재의 흡착 동역학 실험}

전술한 바와 같이 흡착 기작은 복합체형성(complexation), 화학적 흡착(chemisorption), 표면과 모공의 흡착-복합체 형성, 미량침전(micro precipitation), 이온교환(ion exchange) 등이 작용할 수 있으며, 흡착제에 의한 흡착 양상을 해석하기 위해 많은 연구자들이 흡착과정에 대한 해석을 시도해 왔으며 최근 까지 코코넛 껍질이나 소각재, 또는 슬러지를 이용한 흡착은 가역적 일차반응에 준하는 것으로 해석되었다. 그 이후 연구 자들은 화학적 현상으로서 흡착 동역학은 질량 작용 속도 방 정식과 경계 액체 막을 통한 확산에 대한 확산 방정식으로 흡착을 이해하고 유사-일차 반응식에 의해 흡착양상을 적용 하여 방정식의 상수는 입자 직경 및 유속과 무관하며 용액의 

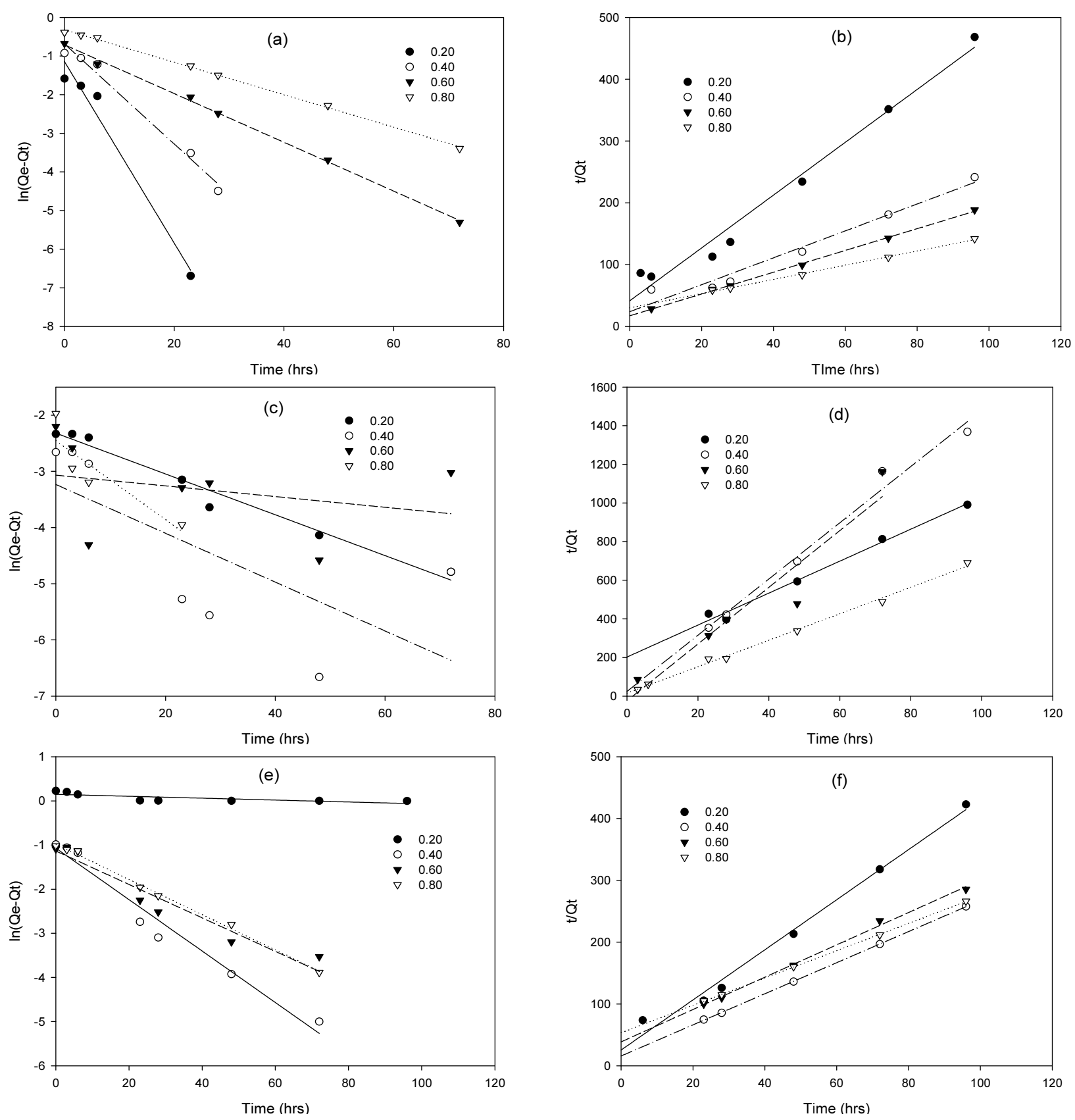

Fig. 4. Linearization of pseudo-first order and pseudo-second order reaction of Fe (a and b), Mn (c and d), Cd (e and f) adsorption in the presence of zeolite.

이온 농도 및 온도에만 의존한다고 해석하였다. 최근 들어 흡 착반응을 유사-이차반응식으로 해석하는 시도가 되고 있으며, 이는 낮은 농도의 흡착물과 흡착제 간의 흡착현상에서 적용이 유효하다고 판단되며, 두 반응식의 특징은 유사-일차반응의 경우 입자 내 확산이 율속제한인자로 작용하고, 유사-이차반 응의 율속제한은 화학적흡착을 따른다고 보고되고 있다. ${ }^{24)}$

본 실험에서 수행된 제올라이트와 황화철 여재에 의한 흡착 특성을 살펴보기 위해 Eq. (3)과 Eq. (5)를 이용하여 유사-일차 반응식 또는 유사-이차반응식을 적용하여 해석하여 보았다. 제올라이트와 황화철 여재의 흡착 동역학을 해석하기 위해
유사- 일차 또는 이차 반응식을 Eq. (4)와 Eq. (6)과 같이 변환 하여 회귀분석 하였으며 그 결과를 Fig.4와 Fig.5에 각각 도 식하였다.

Table 3은 제올라이트와 황화철 여재의 반응차수 별로 회귀 석된 상수값들을 요약하여 정리하였으며, 제올라이트에 의한 각 중금속의 흡착동역학 특성은 유사-일차반응 보다 $(0.086$ $\left.<\mathrm{r}^{2}<0.998\right)$ 유사-이차반응으로 $\left(0.966<\mathrm{r}^{2}<1.000\right)$ 더욱 잘 묘사되었고 황화철 여재 역시 유사-일차반응식의 결정계 수 값이 $\left(0.819<\mathrm{r}^{2}<0.991\right)$ 유사-이차반응으로 회귀분석된 결정계수 값보다 $\left(0.959<\mathrm{r}^{2}<1.000\right)$ 전반적으로 낮게 나왔음 

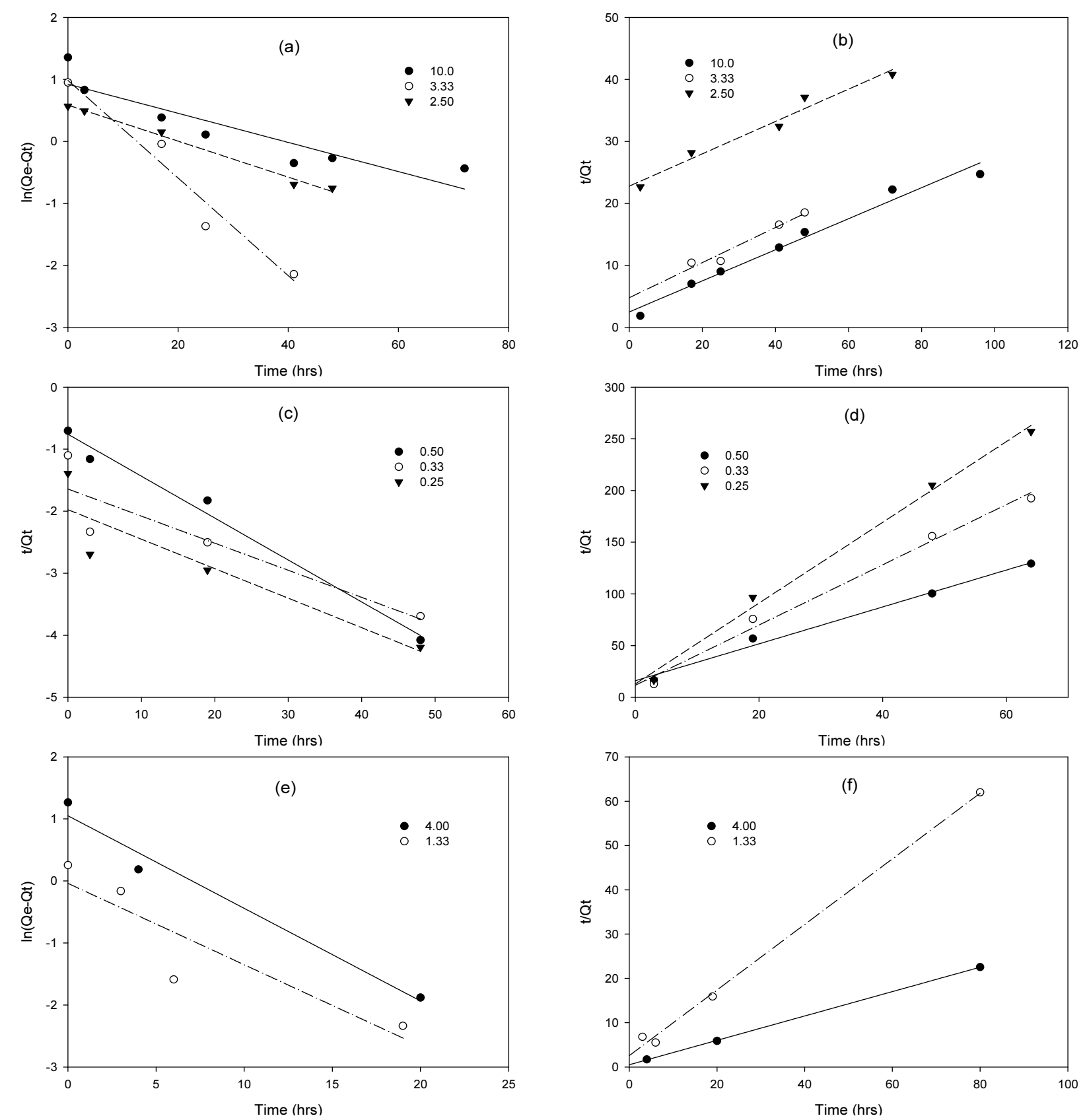

Fig. 5. Linearization of pseudo-first order and pseudo-second order reaction of $\mathrm{Fe}$ (a and b), $\mathrm{Mn}$ ( $\mathrm{C}$ and d), $\mathrm{Cd}$ (e and f) adsorption in the presence of FeS media.

을 알 수 있었다. 이로서 본 실험에서 사용된 $\mathrm{Fe}, \mathrm{Cd}$, 그리고 $\mathrm{Mn}$ 의 경우 제올라이트와 황화철 여재를 통한 흡착 반응이 입자간 분자확산 보다는 화학적 흡착에 의하여 율속 제한된다 는 것을 확인할 수 있었다.

유사-이차 반응식의 반응상수 값( $\left(\mathrm{Ks}_{2}\right)$ 들을 평형상태에서 흡 착량에 도달하는 속도의 관계로 정의된다는 것을 상기하였을 때, Table 3에 산출된 반응상수 값들의 경향은 $\mathrm{Fe}$ 이나 $\mathrm{Cd}$ 의 경우는 낮은 농도에서 평형 흡착량에 도달하는 속도가 빠르다 는 것을 의미한다는 기존의 연구 결과와 ${ }^{24,34}$ 일치하는 것으로 나타났으나 $\mathrm{Mn}$ 의 경우 기존의 연구결과와 다소 상이한 반응
상수 값이 도출되는 것을 고려하였을 때 중금속의 종류에 따 라 흡착량에 도달하는 속도와 중금속의 농도와 상관성은 다르 게 나타날 수 있음을 보여준다.

Table4는 흡착제의 종류에 따라 각 중금속에 흡착 동역학 특성을 요약한 것이다. 흡착제의 종류에 따라 반응차수가 각 각 다르게 나타나고 있어서 일관 형식의 흡착 양상을 기대하 는 것이 어렵다고 판단되었다. 이는 흡착제의 구성이 자연에 서 기인한 원재이고 원재의 구성은 같은 활성탄에서도 구성비 가 다르게 나타날 수 있을 뿐 아니라 점토광물과 같은 형태의 흡착제의 구성은 더욱 다양할 수 있으므로 흡착양상에 대한 
Table 3. Kinetic parameters for the removal of the heavy metals using zeolite and FeS media.

\begin{tabular}{|c|c|c|c|c|c|c|}
\hline \multirow{2}{*}{ Absorbent } & \multirow{2}{*}{\multicolumn{2}{|c|}{$\begin{array}{c}\text { Initial mass of heavy metal/ mass of } \\
\text { absorbent }(\mathrm{mg} / \mathrm{g})\end{array}$}} & \multicolumn{2}{|c|}{ Pseudo-first order reaction } & \multicolumn{2}{|c|}{ Pseudo-second order reactior } \\
\hline & & & $\mathrm{K}_{\mathrm{s} 1}$ & $r^{2}$ & $\mathrm{~K}_{\mathrm{s} 2}$ & $r^{2}$ \\
\hline \multirow{12}{*}{ Zeolite } & \multirow{4}{*}{$\mathrm{Fe}$} & 0.20 & 0.235 & 0.973 & 0.441 & 0.978 \\
\hline & & 0.40 & 0.129 & 0.984 & 0.199 & 0.967 \\
\hline & & 0.60 & 0.063 & 0.998 & 0.180 & 0.999 \\
\hline & & 0.80 & 0.042 & 0.998 & 0.044 & 0.998 \\
\hline & \multirow{4}{*}{$\mathrm{Mn}$} & 0.20 & 0.036 & 0.974 & 0.338 & 0.989 \\
\hline & & 0.40 & 0.043 & 0.505 & 8.851 & 0.985 \\
\hline & & 0.60 & 0.010 & 0.086 & 0.898 & 0.968 \\
\hline & & 0.80 & 0.070 & 0.787 & 3.047 & 0.996 \\
\hline & \multirow{4}{*}{$\mathrm{Cd}$} & 0.20 & 0.002 & 0.568 & 0.647 & 0.989 \\
\hline & & 0.40 & 0.058 & 0.970 & 0.401 & 1.000 \\
\hline & & 0.60 & 0.037 & 0.935 & 0.177 & 0.997 \\
\hline & & 0.80 & 0.040 & 0.996 & 0.091 & 1.000 \\
\hline \multirow{8}{*}{ FeS media } & \multirow{3}{*}{$\mathrm{Fe}$} & 10.0 & 0.024 & 0.826 & 0.025 & 0.978 \\
\hline & & 3.30 & 0.079 & 0.955 & 0.017 & 0.959 \\
\hline & & 2.50 & 0.029 & 0.991 & 0.003 & 0.968 \\
\hline & \multirow{3}{*}{$\mathrm{Mn}$} & 1.00 & 0.068 & 0.986 & 0.199 & 0.991 \\
\hline & & 0.30 & 0.044 & 0.819 & 0.727 & 0.990 \\
\hline & & 0.25 & 0.048 & 0.827 & 1.177 & 0.994 \\
\hline & \multirow{2}{*}{$\mathrm{Cd}$} & 4.00 & 0.150 & 0.976 & 0.146 & 1.000 \\
\hline & & 1.30 & 0.131 & 0.823 & 0.213 & 0.997 \\
\hline
\end{tabular}

Table 4. Comparison of sorption process mechanism according to the adsorbents.

\begin{tabular}{|c|c|c|c|}
\hline Sorbent & Solute & Model & Reference \\
\hline Zeolite & $\mathrm{Cr}^{3+}, \mathrm{Pb}^{2+}, \mathrm{Cd}^{2+}$ & Pseudo-second order & 27) \\
\hline Modified zeolite & $\mathrm{Pb}, \mathrm{Cu}, \mathrm{Zn}, \mathrm{Mn}, \mathrm{Ni}, \mathrm{Cd}$ & Pseudo-second order & 29) \\
\hline Illite & $\mathrm{Pb}^{2+}$ & Pseudo-second order & 30) \\
\hline Kaolinite & $\mathrm{Cu}^{2+}, \mathrm{Ni}^{2+}, \mathrm{Zn}^{2+}$ & Pseudo-second order & 31) \\
\hline Montmorillonite & $\mathrm{Cu}^{2+}, \mathrm{Ni}^{2+}$ & Pseudo-second order & 32) \\
\hline Kaolinitic clay & $\mathrm{Pb}^{2+}$ & First order & 35) \\
\hline Wollastonite & $\mathrm{Ni}^{2+}$ & Pseudo-first order & 36) \\
\hline Rod-shaped phillipsite & $\mathrm{Ni}^{2+}$ & Pseudo-first order & 37) \\
\hline Zeolite & $\mathrm{Cd}, \mathrm{Ni}$ & Pseudo-first order & 38) \\
\hline Fly ash & $\mathrm{F}^{-}, \mathrm{Cu}^{2+}$ & First order & $39,40)$ \\
\hline Activated carbon & $\begin{array}{l}\mathrm{CN}- \\
\mathrm{Cr}(\mathrm{VI})\end{array}$ & $\begin{array}{c}\text { First order } \\
\text { second order }\end{array}$ & $\begin{array}{l}41) \\
42)\end{array}$ \\
\hline Algae-biosorbent & $\mathrm{Pb}$ & Pseudo-second order & 43) \\
\hline FeS media & $\mathrm{Fe}^{2+}, \mathrm{Mn}^{2+}, \mathrm{Cd}^{2+}$ & Pseudo-second order & This study \\
\hline Zeolite & $\mathrm{Fe}^{2+}, \mathrm{Mn}^{2+}, \mathrm{Cd}^{2+}$ & Pseudo-second order & This study \\
\hline
\end{tabular}

예상은 흡착제의 종류와 상관없이 실험에 의해 규정되어야 한다고 판단된다. 따라서 본 실험에서 도출된 결과와 기존의 흡착제의 흡착반응의 반응차수를 비교하여 보았다.

Table 4에서 보여지는바와 같이 Zeolite, kaolinitic clay, wollastonite, 또는 phillipsite와 같은 점토성 입자에서는 용액 상 막의 확산이나 내부 입자의 확산이 반응제한요소가 되는
유사-일차반응이 적합하게 적용되는 것으로 보고된 바 있으 며 illite나 montmorillonite의 경우 화학결합을 율속제한인자 로 가지는 유사-이차반응으로 반응차수의 적합도가 나타나는 것으로 보고되었다. Table 4에 제시된 흡착제 중 kaolinite, activated carbon, 또는 zeolite의 경우 유사-일차반응과 유사이차반응의 흡착양상을 같이 나타내고 있는 바, 이는 중금속 
의 종류나 흡착제의 종류 또는 구성성분에 따라 중금속의 동 역학 양상은 각각 다르게 나타날 수 있다는 것을 보여준다. 이는 자연에서 생성된 흡착제의 생성 과정의 다양성이 흡착반 응의 형태를 다양하게 나타내는 것이라고 판단되었다. 따라서 기존의 연구에서 제안한 것과 같이 천연제올라이트나 파이라 이트와 같은 천연 흡착제의 실 적용에 있어서 반응차수의 해 석이 우선적으로 선행되어야 한다. ${ }^{34)}$ 본 실험에서 행해진 제 올라이트와 황화철 여재를 이용한 중금속 흡착 반응은 유사이차반응으로 해석되었으며, 본 연구에서 도출된 흡착의 형태 는 타 연구자들이 $\mathrm{Fe}, \mathrm{Mn}$, 그리고 $\mathrm{Cd}$ 의 흡착반응을 이해하는 자료로 활용될 수 있을 것으로 판단된다.

\section{4. 결 론}

본 실험에서는 제올라이트와 황화철 여재를 이용하여 수 중에서 중금속 $(\mathrm{Fe}, \mathrm{Mn}, \mathrm{Cd})$ 의 흡착 특성을 알아보았다. Freundlich와 Langmuir 등온흡착식 그리고 유사-일차, 유사이차 반응식을 이용하여 흡착특성을 해석하였을 때 도출된 결과를 아래에 요약 정리하였다.

1) 두 여재의 흡착특성을 살펴보았을 때, Freundlich 등온 흡착식에서 제올라이트나 황화철 여재에 의한 $\mathrm{Fe}, \mathrm{Mn}$, 그리 고 $\mathrm{Cd}$ 의 흡착은 모두 $\mathrm{n}>1$ 이므로 $(6.878>\mathrm{n}>1.100)$ 비우호 적인 흡착양상을 나타내는 것으로 확인되었다. Langmuir 등 온 흡착식의 흡착 선호도를 비교하기 위해 $\mathrm{R}_{\mathrm{L}}=1 /\left(1+\mathrm{b} \cdot \mathrm{C}_{0}\right)$ 을 이용하였으며, $\mathrm{Fe}, \mathrm{Mn}$, 그리고 $\mathrm{Cd}$ 의 흡착의 경우 $0<\mathrm{R}_{\mathrm{L}}<$ 1 이므로 $\left(1.60 \times 10^{-1}>\mathrm{R}_{\mathrm{L}}>8.03 \times 10^{-3}\right)$ Langamuir 등온 흡착 식에서 우호적인 흡착형태를 가지는 것으로 나타났다. 흡착특 성에 대한 적합성을 구하기 위해 회귀분석 값은 결정계수 $\left(r^{2}\right)$ 를 확인해본 결과 Langamuir 식은 $0.908<\mathrm{r}^{2}<0.998$ 인 반면 Freundlich 직선화에 따른 결정계수는 $0.781<\mathrm{r}^{2}<0.999$ 으로 단층 흡착의 특성을 가진 Langamuir 등온흡착식에 더 적합하 다는 것을 알 수 있었다.

2) 제올라이트의 최대 흡착능은 $\mathrm{Fe}$ 에서 가장 높게 나타났으 며, $\left(\mathrm{q}_{\mathrm{m}}\right.$ of $\mathrm{Fe}=0.791 \mathrm{mg} / \mathrm{g} ; \mathrm{q}_{\mathrm{m}}$ of $\mathrm{Mn}=0.081 \mathrm{mg} / \mathrm{g} ; \mathrm{q}_{\mathrm{m}}$ of $\mathrm{Cd}=0.546 \mathrm{mg} / \mathrm{g}$ ), 흡착 선호도는 $\mathrm{Fe}>\mathrm{Cd}>\mathrm{Mn}$ 순으로 나타 난다. 황화철 여재의 경우 $\mathrm{Cd}$ 가 $\mathrm{Fe}$ 나 $\mathrm{Mn}$ 에 비하여 높은 최대 흡착능 $\left(\mathrm{q}_{\mathrm{m}}\right.$ of $\mathrm{Fe}=4.424 \mathrm{mg} / \mathrm{g} ; \mathrm{q}_{\mathrm{m}}$ of $\mathrm{Mn}=0.472 \mathrm{mg} / \mathrm{g} ; \mathrm{q}_{\mathrm{m}}$ of $\mathrm{Cd}=4.814 \mathrm{mg} / \mathrm{g}$ )을 가지는 것으로 나타났으며, 흡착 선호도 는 $\mathrm{Cd}>\mathrm{Fe}>\mathrm{Mn}$ 인 것으로 관찰되었다. Langmuir 등온흡착식 의 최대흡착량 $\left(\mathrm{q}_{\mathrm{m}}\right)$ 으로 제올라이트와 황화철 여재의 흡착능 을 비교하였을 때 $\mathrm{Fe}$ 이나 $\mathrm{Mn}, \mathrm{Cd}$ 의 경우 모두 황화철 여재가 더 효과적이라는 것을 알 수 있었다.

3) 유사-일차반응식 또는 유사-이차반응으로 회귀분석된 결과로 보았을 때 제올라이트에 의한 유사-일차반응식 회귀 분석의 $r^{2}$ 값이 $\left(0.086<r^{2}<0.998\right)$ 유사-이차반응으로 회귀 분석된 결과보다 $\left(0.966<\mathrm{r}^{2}<1.000\right)$ 낮게 산출되었다. 황화
철 여재의 경우에도 유사-일차반응식 회귀분석의 결정계수 값이 $\left(0.819<\mathrm{r}^{2}<0.991\right)$ 유사-이차반응으로 회귀분석된 결 과보다 $\left(0.959<\mathrm{r}^{2}<1.000\right)$ 전반적으로 낮게 나왔음을 알 수 있었다. 이는 제올라이트 또는 황화철 여재에 중금속 $(\mathrm{Fe}$, $\mathrm{Mn}, \mathrm{Cd}$ )의 흡착은 화학적 흡착에 의한다는 것을 나타낸다.

본 연구를 통하여 $\mathrm{Fe}, \mathrm{Mn}$, 그리고 $\mathrm{Cd}$ 과 같은 2가 양이온 중금속 처리에 있어서 제올라이트와 황화철 여재가 효과적인 중금속 처리 수단이 될 수 있음을 확인하였다. 단, 중금속의 종류와 농도에 따라 흡착 특성이 다르게 나타날 수 있다는 점을 상기하였을 때, $\mathrm{As}$ 나 $\mathrm{Cr}$ 과 같은 다가 이온의 중금속 흡착 에 대한 연구가 추가적으로 진행되어 다양한 중금속들의 흡착 양상을 종합적으로 살펴보는 것이 필요하다고 판단되었다.

\section{Acknowledgement}

본 연구는 한국연구재단 기초과학연구프로그램 지원사업 (2020R1A6A1A0304274211)으로 수행되었으며, 이에 감사드 립니다.

\section{References}

1. M. S. Islam, M. K. Ahmed, M. Raknuzzaman, M. HabibullahAl-Mamun, M. K. Islam, Heavy metal pollution in surface water and sediment: a preliminary assessment of an urban river in a developing country, Ecol. indic., 48, 282-291 (2015).

2. D. Kar, P. Sur, S. K. Mandai, T. Saha, R. K. Kole, Assessment of heavy metal pollution in surface water, Int. J. Environ. Sci. Technol., 5(1), 119-124(2008).

3. Q. Yang, Z. Li, X. Lu, Q. Duan, L. Huang, J. Bi, A review of soil heavy metal pollution from industrial and agricultural regions in China: pollution and risk assessment, Sci. Total Environ., 642, 690-700(2018).

4. K. H. Vardhan, P. S. Kumar, R. C. Panda, A review on heavy metal pollution, toxicity and remedial measures: current trends and future perspectives, J. Mol. Liq., 290, 111197(2019).

5. J. P. Vareda, A. J. M. Valente, L. Durães, Assessment of heavy metal pollution from anthropogenic activities and remediation strategies: a review, J. Environ. Manage., 246, 101-118(2019).

6. C. V. Mohod, J. Dhote, Review of heavy metals in drinking water and their effect on human health, Inter. J. Innov. Res. Sci., 7(2), 2292-2296(2013).

7. C. Lu, K. R. Svoboda, K. A. Lenz, C. Pattison, H. Ma, Toxicity interactions between manganese $(\mathrm{Mn})$ and lead $(\mathrm{Pb})$ or cadmium $(\mathrm{Cd})$ in a model organism the nematode $\mathrm{C}$. elegans, Environ. Sci. Pollut. Res., 25(16), 15378-15389(2018).

8. G. Li, H. J. Kronzucker, W. Shi, Root developmental adaptation to $\mathrm{Fe}$ toxicity: mechanisms and management, 
Plant. Signal. Behav., 11(1), e1117722(2016)

9. J. K. Yoon, D. H. Kim, T. S. Kim, J. G. Park, I. R. Chung, J. H. Kim, H. Kim, Evaluation on natural background of the soil heavy metals in Korea, J. Soil Groundwater Environ., 14(3), 32-39(2009).

10. Y. Zhang, X. Duan, Chemical precipitation of heavy metals from wastewater by using the synthetical magnesium hydroxy carbonate, Wat. Sci. Technol., 81(6), 1130-1136(2020).

11. S. E. Bailey, T. J. Olin, R. M. Bricka, D. D. Adrian, A review of potentially low-cost sorbents for heavy metals, Water res., 33(11), 2469-2479(1999).

12. A. Bashir, L. A. Malik, S. Ahad, T. Manzoor, M. A. Bhat, G. N. Dar, A. H. Pandith, Removal of heavy metal ions from aqueous system by ion-exchange and biosorption methods, Environ. Chem. Lett., 17(2), 729-754(2019).

13. S. Tangjuank, N. Insuk, J. Tontrakoon, V. Udeye, Adsorption of Lead (II) and Cadmium(II) ions from aqueous solutions by adsorption on activated carbon prepared from cashew nut shells, World Acad. Sci. Eng. Technol., 3(4), 221-227(2009).

14. N. Abdullah, N. Yusof, W. J. Lau, J. Jaafar, A. F. Ismail, Recent trends of heavy metal removal from water/ wastewater by membrane technologies, J. Ind. Eng. Chem., 76, 17-38(2019).

15. L. Monser, N. Adhoum, Modified activated carbon for the removal of copper, zinc, chromium and cyanide from wastewater, Separ. Purif. Technol., 26(2-3), 137-146(2002).

16. R. Say, E. Birlik, A. Denizli, A. Ersoz, Removal of heavy metal ions by dithiocarbamate-anchored polymer/organosmectite composites, Appl. Clay Sci., 31(3-4), 298-305(2006).

17. F. Fu, H. Zeng, Q. Cai, R. Qiu, J. Yu, Y. Xiong, Effective removal of coordinated copper from wastewater using a new dithiocarbamate-type supramolecular heavy metal precipitant, Chemosphere, 69(11), 1783-1789(2007).

18. L. Bai, H. Hu, W. Fu, J. Wan, X. Cheng, L. Zhuge, L. Xiong, Q. Chen, Synthesis of a novel silica-supported dithiocarbamate adsorbent and its properties for the removal of heavy metal ions, J. Hazard. Mater., 195, 261-275(2011).

19. R. Abu-Ei-Halawa, S. A. Zabin, Removal efficiency of $\mathrm{Pb}$, $\mathrm{Cd}, \mathrm{Cu}$ and $\mathrm{Zn}$ from Polluted water using dithiocarbamate ligands, J. Taibah. Univ. Sci., 11(1), 57-65(2017).

20. C. F. Carolin, P. A. Kumar, A. Saravanana, G. J. Joshiba, M. Naushad, Efficient techniques for the removal of toxic heavy metals from aquatic environment: a review, J. Environ. Chem. Eng., 5(3), 2782-2799(2017).

21. A. S. Mollamahmutoglu, G. Kanat, F. I. Turkdogan, Pollution removal from leachate using bottom ash-bentonite-zeolite liner, Desalin. Water Treat., 160, 178-184(2019).

22. J. Wen, H. Dong, G. Zeng, Application of zeolite in removing salinity/sodicity from wastewater: a review of mechanisms, challenges and opportunities, J. Clean. Prod., 197, 1435-1446(2018).

23. A. S. Thajeel, Isotherm, kinetic and thermodynamic of adsorption of heavy metal ions onto local activated carbon, Aquat. Sci. Technol., 1(2), 53-77(2013).

24. Y. S. Ho, G. McKay, Pseudo-second order model for sorption processes, Process. Biochem., 34(5), 451-465(1999).

25. Korean Law Information Center Home page, https://www. law.go.kr/flDownload.do?flSeq=95786721, February(2021).

26. U.S. Enviromental Protection Agency Home Page, https:// www.epa.gov/hw-sw846/sw-846-test-method-7000b-flameatomic-absorption-spectrophotometry, February(2007).

27. K. O. Sulaiman, M. Sajid, K. Alhooshani, Application of porous membrane bag enclosed alkaline treated Y-Zeolite for removal of heavy metal ions from water, Microchem. J, 152, 104289(2020).

28. T. P. Belova, Adsorption of heavy metal ions $\left(\mathrm{Cu}^{2+}, \mathrm{Ni}^{2+}\right.$, $\mathrm{Co}^{2+}$ and $\mathrm{Fe}^{2+}$ ) from aqueous solutions by natural zeolite, Heliyon, 5(9), e02320(2019).

29. Q. Qiu, X. Jiang, G. Lv, Z. Chen, S. Lu, M. Ni, X. Deng, Adsorption of heavy metal ions using zeolite materials of municipal solid waste incineration fly ash modified by microwave-assisted hydrothermal treatment, Powder Technol., 335, 156-163(2018).

30. J. Yin, C. Deng, Z. Yu, X. Wang, G. Xu, Effective removal of lead ions from aqueous solution using nano illite/smectite clay: isotherm, kinetic, and thermodynamic modeling of adsorption, Water, 10(2), 210(2018).

31. A. M. Alasadi, F. I. Khaili, A. M. Awwad, Adsorption of $\mathrm{Cu}(\mathrm{II}), \mathrm{Ni}(\mathrm{II})$ and $\mathrm{Zn}(\mathrm{II})$ ions by nano kaolinite: thermodynamics and kinetics studies, Chem. Int., 5(4), 258-268 (2019).

32. N. D. Mu'azu, A. Bukhari, K. Munef, Effect of montmorillonite content in natural Saudi Arabian clay on its adsorptive performance for single aqueous uptake of $\mathrm{Cu}$ (II) and Ni(II), J. King. Saud. Univ. Sci., 32(1), 412-422(2020).

33. I. N. C. E. Muharrem, O. K. Ince, An overview of adsorption technique for heavy metal removal from water/wastewater: a critical review, Int. J. Pure. Appl. Sci, 3(2), 10-19(2017).

34. K. Lee, K. Kim, S. Choi, T. J. Lee, A Study on adsortion of heavy metals with granule type of zeolite and FeS media, J. Korean Soc. Environ. Eng., 42(7), 349-359(2020).

35. F. F. O. Orumwense, Removal of lead from water by adsorption on a kaolinitic clay, J. Chem. Technol. Biotechnol., 65(4), 363-369(1996).

36. Y. C. Sharma, G. S. Gupta, G. Prasad, D. C. Rupainwar, Use of wollastonite in the removal of Ni (II) from aqueous solutions, Water. Air. Soil. Pollut. 49(1-2), 69-79(1990).

37. P. Y. He, Y. J. Zhang, H. Chen, Z. C. Han, L. C. Liu, Onestep synthesis of rod-shaped phillipsite using circulating fluidized bed fly ash and its application for removal heavy metal, Ferroelectr., 547(1), 51-58(2019).

38. K. He, Y. Chen, Z. Tang, Y. Hu, Removal of heavy metal ions from aqueous solution by zeolite synthesized from fly ash, Environ. Sci. Pollut. Res. Int, 23(3), 2778-2788(2016).

39. K. K. Panday, G. Prasad, V. N. Singh, Copper (II) removal from aqueous solutions by fly ash, Water Res., 19(7), 869-873(1985).

40. A. K. Chaturvedi, K. P. Yadava, K. C. Pathak, V. N. Singh, Defluoridation of water by adsorption on fly ash, Water Air Soil Pollut., 49(1), 51-61(1990). 
41. J. S. J. Van Deventer, P. F. Van der Merwe, Kinetic model for the decomposition of cyanide during the elution of gold from activated carbon, Sep. Sci. Technol., 30(6), 883-898 (1995).

42. D. C. Sharma, C. F. Forster, The treatment of chromium wastewaters using the sorptive potential of leaf mould, Biores. Technol., 49(1), 31-40(1994).

43. C. H. Lee, K. H. Ahn, Biosorption of lead ions onto Laminaria japonica and Kjellmaniella crassifolia: equilibrium and kinetic modelling, J. Korean Soc. Environ. Eng., 27(11), 1238-1243(2005).

\section{Declaration of Competing Interest}

The authors declare that they have no known competing financial interests or personal relationships that could have appeared to influence the work reported in this paper.

\section{Authors and Contribution Statement}

\section{Sung-kyu Choi}

Department of Environmental Energy Engineering, Graduate School of Convergence Science, Seoul National University of Science and Technology, Researcher, ORCID (ㄷ) 0000-0002-1636 -260X: Data curation, Data analysis, Writing - original draft, Writing - review and editing.

\section{Min-jun Kim}

Department of Environmental Engineering, Seoul National University of Science and Technology, Researcher, ORCID(1) 0000-0003-4609-7795: Data curation, Methodology, Visualization.

\section{Tae-geon Kim}

Department of Environmental Engineering, Seoul National University of Science and Technology, Researcher, ORCID(1) 0000-0003-2203-495X: Data curation, Data analysis.

\section{Tae-jin Lee}

Department of Environmental Engineering, Seoul National University of Science and Technology, Professor, ORCID 10000 0001-9532-5358: Conceptualization, Methodology, Visualization, Writing - original draft, Writing -review and editing. 